\title{
Non Valvular Atrial Fibrillation Related Ischaemic Stroke at the Teaching Hospital of Yalgado Ouédraogo, Burkina Faso
}

Mandi D Germain ${ }^{1}$, Samadoulougou K André1,2, Yaméogo R Aristide ${ }^{1 *}$, Millogo RC Georges ${ }^{1,2}$, Naïbé D Temoua ${ }^{1}$, Kaboré PK Hervé1, Kologo K Jonas ${ }^{1}$ and Zabsonré Patrice ${ }^{1,2}$

${ }^{1}$ Service de Cardiologie du Centre Hospitalier Universitaire Yalgado Ouédraogo (CHU-YO), Burkina Faso

${ }^{2}$ Unité de Formation et de Recherche en Sciences de la Santé/ Université de Ouagadougou, Burkina Faso

\begin{abstract}
Objectives: We aim to describe the epidemiological and prognostic characteristics of non valvular atrial fibrillation related stroke.

Patients and methods: We retrospectively analyzed data of hospitalized patients from January $1^{\text {st }} 2010$ to June $30^{\text {th }} 2012$ in the two contiguous departments of cardiology and neurology, at the teaching hospital of Yalgado Ouédraogo, Burkina Faso.

Results: We recorded 391 cases of ischaemic stroke. Cardioembolic stroke was observed in 159 patients out of who, non valvular atrial fibrillation accounted for $43.5 \%$. Atrial fibrillation was persistent/permanent in 60 cases (87\%). The mean age \pm SD was $63.3 \pm 14.2$ years (extremes: $26-91$ years). Hypertension was observed in $85.5 \%$ of the cases. The mean $\mathrm{CHA}_{2} \mathrm{DS}_{2}-\mathrm{VASc}$ score was $4.72 \pm 1.16$. The mean HAS-BLED score was $2.35 \pm 0.92$ with a low to intermediate bleeding risk score $(\leq 2)$ in $60.9 \%$ of patients. The rate of vitamin $\mathrm{K}$ antagonists use was $52 \%$. They were introduced at least a week after stroke onset in 34 cases. A mean follow up of two weeks in hospital noticed haemorrhagic transformation and ischaemic recurrence in respectively $8.7 \%$ and $2.9 \%$ of the cases. Mortality rate of $21.7 \%$ during hospitalization was predicted by large sized cerebral infarction and congestive heart failure $(p<0.05)$.

Conclusion: Non valvular atrial fibrillation stroke is associated with in-hospital high mortality and is subject to early recurrence.
\end{abstract}

Keywords: Ischaemic stroke; Non valvular atrial fibrillation; Anticoagulation; Hemorrhagic transformation; Mortality; Burkina Faso

\section{Introduction}

Ischaemic stroke is a leading cause of acquired disability and death in adults [1]. Cardioembolic stroke accounts for $14-30 \%$ of all ischaemic strokes and appears to be associated with higher mortality and early recurrence $[2,3]$. Atrial fibrillation (AF) is the most common cardiac source of cerebral embolism with many associated risk factors $[4,5]$. Managing AF alone or with stroke is challenging and costly [68]. Data regarding AF related stroke are scarce in Sub-Saharan African including Burkina Faso. We aim to describe the epidemiological and prognostic characteristics of Non Valvular Atrial Fibrillation (NVAF) related stroke during hospitalization period.

\section{Patients and Methods}

We retrospectively analyzed data of hospitalized patients from January $1^{\text {st }} 2010$ to June $30^{\text {th }} 2012$ in the two contiguous departments of cardiology and neurology, at the teaching hospital of Yalgado Ouédraogo, Burkina Faso, west Africa. Those were included in the study, patients with ischaemic stroke diagnosed by cranial Computed Tomographic (CT) scan and/or by clinical stroke (persistence of focal neurological symptoms for over 24 hours period) who presented AF confirmed by a standard 12-lead electrocardiogram (ECG) or 24-hours Holter ECG. Transthoracic echocardiography (TTE) was used to screen patients with non valvular AF in the absence of rheumatic or degenerative cardiac valvular disease and valvular prosthesis.

TTE and transoesophageal echocardiography (TOE) were performed to look for other concomitant cardiac sources of cerebral embolism [9]. Doppler ultrasonography was used to eliminate cervical large-artery atherosclerotic sources of embolism (obstructive carotid and vertebro-basilar artery disease).

Lone $\mathrm{AF}$ was defined as a condition without associated concomitant cardiac source of embolism. The cerebral infarction was assumed largesized in case of infarct diameter above $30 \mathrm{~mm}$ at baseline. Congestive heart failure included shortness of breath weakness, edema, rales, rhonchi, or wheezes, presence of a third or fourth heart sound. Left ventricular ejection fraction (LVEF) was assessed by TTE in all patients. Urban area was defined by both Ouagadougou and BoboDioulasso, the two biggest cities of Burkina Faso where International Normalized Ratio (INR) could be performed. Thromboembolic risk was evaluated according to CHA2DS2Vasc score [10]. Bleeding risk stratification was based on HAS-BLED score [11]. Cardiovascular vascular risk factors were evaluated according to the 2013 European Society of Hypertension/European Society of Cardiology [12].

For statistical analysis, EPI info TM software (version 7.0.9.34) was used. The categorical variables were expressed as percentages.

*Corresponding author: Yameogo R Aristide, Service de Cardiologie du Centre Hospitalier Universitaire Yalgado Ouédraogo (CHU-YO), P.O: 11 BP 804 CMS Ouagadougou 11, Burkina Faso, Tel: 00226-66 4858 58; E-mail: yraristide@hotmail.fr

Received December 02, 2014; Accepted December 16, 2014; Published December 18, 2014

Citation: Mandi DG, Samadoulougou AK, Yameogo RA, Millogo GRC, Naibe DT, et al. (2015) Non Valvular Atrial Fibrillation Related Ischaemic Stroke at the Teaching Hospital of Yalgado Ouédraogo, Burkina Faso. J Vasc Med Surg 3: 171. doi:10.4172/2329-6925.1000171

Copyright: ( 2015 Mandi DG, et al. This is an open-access article distributed under the terms of the Creative Commons Attribution License, which permits unrestricted use, distribution, and reproduction in any medium, provided the original author and source are credited. 
Citation: Mandi DG, Samadoulougou AK, Yameogo RA, Millogo GRC, Naibe DT, et al. (2015) Non Valvular Atrial Fibrillation Related Ischaemic Stroke at the Teaching Hospital of Yalgado Ouédraogo, Burkina Faso. J Vasc Med Surg 3: 171. doi:10.4172/2329-6925.1000171

Page 2 of 5

Continuous variables were expressed in terms of means \pm SD. Chi square test or Fisher's exact test were used for proportions comparison as appropriate. A logistic regression model was used to identify risk factors independently associated with death. For each analysis, a significant difference was defined as $\mathrm{p}<0.05$.

\section{Results}

During the study period, 2010 patients were hospitalized at both departments. We recorded 391 cases of ischaemic stroke. Cardioembolic stroke was observed in 159 patients out of who, NVAF accounted for $43.5 \%$ (43 females and 26 males). Atrial fibrillation was persistent/ permanent in 60 cases $(87 \%)$ and paroxystic in nine cases (13\%). The mean age was $63.3 \pm 14.2$ years (extremes: $26-91$ years). Forty five patients $(65.2 \%)$ were $\geq 60$ years old. Cardiovascular risk factors included hypertension in $85.5 \%(\mathrm{n}=59)$, dyslipidemia in $24.6 \%$ $(\mathrm{n}=17)$ and diabetes in $21.7 \%(\mathrm{n}=15)$ of patients. Alcohol abuse was observed in 25 cases (36.2\%). Neurological deficit occurred in 63 cases and congestive heart failure was noticed in nine patients. The sociodemographic and clinical characteristics of the study patients at admission are shown in Table 1.

Cranial CT scan was normal in four cases (5.8\%) and found a hypodensity in 65 cases (94.2\%). The localization of such lesion was unique in $61.5 \%$ and had multiple foci in $38.5 \%$ of patients. The cerebral infarct was large-sized in 18 patients (27.7\%).

Concomitant potential cardiac sources of ischaemic stroke were noticed in 45 cases $(65.2 \%)$. These underlying sources included hypertensive dilated cardiomyopathy in 15 cases and left sided thrombus in 10 cases (Table 2). Mean LVEF was $61.6 \% \pm 14.6(28$ 80 ). Eight patients had a LVEF $<40 \%$ and eleven had a LVEF between 40 and $54 \%$. Cervical arterial Doppler ultrasonography performed in 28 patients has shown plaque in 23 cases without significant atherothrombotic stenosis $(<50 \%)$.

The mean CHA2DS2-VASc score was $4.72 \pm 1.16$ (extremes 2 and 7) and all patients had high thromboembolic risk. The mean HAS-BLED score was $2.35 \pm 0.92$ (extremes: 1 and 5) with a low to intermediate bleeding risk score $(\leq 2)$ in $60.9 \%$ of patients (Figure 1 ). Characteristics comprising both CHA2DS2-Vasc stroke risk score and HAS-BLED bleeding risk are shown in Table 3.

Low molecular weight heparin (LMWH), enoxaparin in our context was used for secondary prevention of stroke recurrence in 55 patients before switching to vitamin $\mathrm{K}$ antagonist (VKA) in 36 cases (52\%). VKA were introduced at least a week after stroke onset in 34 cases and sooner in two cases. VKA were prescribed in $60.9 \%(n=31)$ of 51 patients without large sized cerebral infarction versus $27.8 \%(n=5)$ of those with larger cerebral infarction $(\mathrm{RR}=2.19$; CI95\%= $1.01-4.76]$; $\mathrm{p}=0.02$ ). VKA treatment was observed in $66.7 \%$ of the 42 patients from urban area versus $29.6 \%$ of 27 patients from other areas $(R R=2.25$; $\mathrm{CI} 95 \%=[1.21-4.18] ; \mathrm{p}=0.003)$. Antiplatelet therapy was prescribed in $94.2 \%$ of the study patients. It was associated with VKA in 35 cases and used alone in 14 patients. Ventricular rate control was obtained using antiarrhythmic drug in 55\% of the cases comprising amiodarone $(n=14), \beta$-blockers $(n=19)$ and digoxine $(n=5)$. Table 4 indicates therapy received by study population during hospitalization period.

A mean follow up of 12.8 days \pm 7.8 (extremes: two and 45 days) in hospital noticed complete regression of neurological deficit in 18 patients $(26.1 \%)$. Complications were observed in 17 patients including haemorrhagic transformation in $8.7 \%(\mathrm{n}=6)$, seizures in $8.7 \%(n=6)$ and ischaemic stroke recurrence in $2.9 \%(n=3)$. Five out of 18 patients with larger cerebral infarct developed haemorrhagic transformation $(\mathrm{RR}=14.17$; $\mathrm{CI} 95 \%=[1.77-113.25] ; \mathrm{p}=0.003)$. Only three patients among those under VKA $(\mathrm{n}=36)$ developed haemorrhagic transformation $(\mathrm{RR}=0.41$; $\mathrm{CI} 95 \%=[0.09-2.34]$; $\mathrm{p}=0.46)$. Mortality rate during hospitalization period was $21.7 \%(\mathrm{n}=15)$. It was associated on univariate analysis with older age $\geq 75$ years, large sized cerebral infarct, haemorrhagic transformation and congestive heart failure. On multivariate analysis, large sized cerebral infarct and congestive heart failure were independent and significant predictor death (Table $5)$. Immediate cause of death was of cardiac $(n=4)$ and neurological $(n=7)$ origin. Table 6 showed distribution of complications and causes of death in study population.

\begin{tabular}{|c|c|c|}
\hline Characteristic & Number (n) & Percentage (\%) \\
\hline Mean age (years) & $63.3 \pm 14.2$ & - \\
\hline \multicolumn{3}{|l|}{ Age rage } \\
\hline$<60$ & 11 & 16 \\
\hline $60-74$ & 45 & 65.2 \\
\hline$\geq 75$ & 13 & 18.8 \\
\hline Females/Males & $43 / 26$ & $62.3 / 37.7$ \\
\hline \multicolumn{3}{|l|}{ Type of atrial fibrillation } \\
\hline Paroxystic & 9 & 13 \\
\hline Persistent & 17 & 24.6 \\
\hline Long-standing persistent & 19 & 27.5 \\
\hline Permanent & 24 & 34.8 \\
\hline \multicolumn{3}{|l|}{ Cardiovascular risk factors } \\
\hline Hypertension & 59 & 85.5 \\
\hline Dyslipidemia & 17 & 24.6 \\
\hline Smoking & 17 & 24.6 \\
\hline Diabetes mellitus & 15 & 21.7 \\
\hline Obesity & 10 & 14.5 \\
\hline Prior ischaemic stroke & 12 & 17.4 \\
\hline \multicolumn{3}{|l|}{ Clinical features } \\
\hline Congestive heart failure & 9 & 13 \\
\hline Pure motor weakness & 63 & 91.3 \\
\hline Impaired verbal processing & 42 & 60.9 \\
\hline Weakness of face & 26 & 37.7 \\
\hline Association of the three types of deficit & 43 & 62.3 \\
\hline Syncope & 21 & 30.4 \\
\hline Altered consciousness & 11 & 16 \\
\hline Palpitations & 19 & 27.5 \\
\hline Ongoing antiplatelet therapy & 19 & 27.5 \\
\hline
\end{tabular}

Table 1: Socio-demographic and clinical characteristics of study patients at baseline.

\begin{tabular}{|l|r|r|}
\hline $\begin{array}{l}\text { Concomitant potential cardiac sources of } \\
\text { embolism }\end{array}$ & Number (n) & Percentage (\%) \\
\hline High-risk sources of embolism & \multicolumn{2}{|l|}{} \\
\hline Hypertensive dilated cardiomyopathy & 15 & 21.7 \\
\hline Cardiothyreosis† & 2 & 2.9 \\
\hline Left sided thrombus & 10 & 14.5 \\
\hline Restrictive cardiomyopathy & 4 & 5.8 \\
\hline Medium-risk sources of embolism & 16 & \\
\hline Spontaneous echo contrast & 2 & 23.2 \\
\hline Hypertrophic hypertensive cardiomyopathy & 5 & 2.9 \\
\hline Ischaemic cardiomyopathy (>4 weeks) & 2 & 7.3 \\
\hline Patent foramen ovale & 1 & 2.9 \\
\hline Communicant interatrial septal aneurysm & & 1.4 \\
\hline
\end{tabular}

Table 2: Concomitant potential cardiac sources of cerebral embolism in 69 patients (†with dilated left cavities). 
Citation: Mandi DG, Samadoulougou AK, Yameogo RA, Millogo GRC, Naibe DT, et al. (2015) Non Valvular Atrial Fibrillation Related Ischaemic Stroke at the Teaching Hospital of Yalgado Ouédraogo, Burkina Faso. J Vasc Med Surg 3: 171. doi:10.4172/2329-6925.1000171

Page 3 of 5

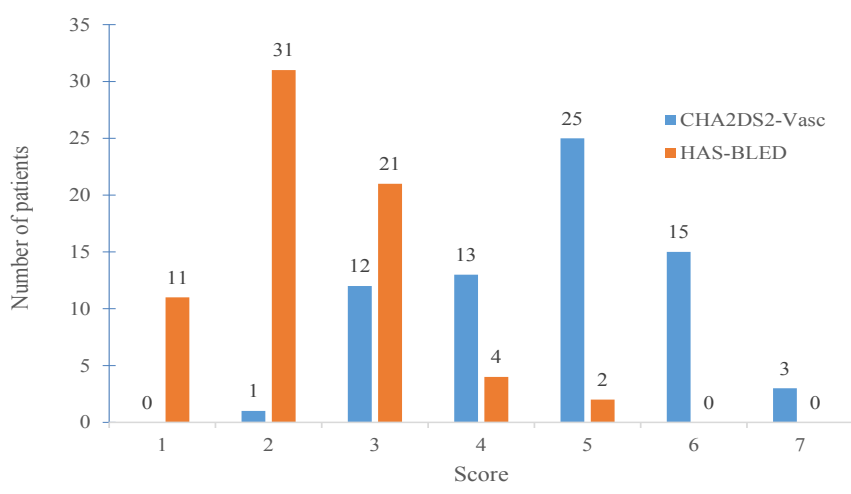

Figure 1: Distribution of all 69 patients with non valvular atrial fibrillation according to $\mathrm{CHA}_{2} \mathrm{DS}_{2}$-Vasc and HAS-BLED scores.

\begin{tabular}{|l|r|r|}
\hline Risk factor & Number & Percentage \\
\hline Thromboembolic risk factors $\left(\mathrm{CHA}_{2} \mathrm{DS}_{2}\right.$-Vasc) & 14 & 20.3 \\
\hline Congestive heart failure/ LVEF $<0,40$ & 59 & 85.5 \\
\hline Hypertension & 13 & 18.8 \\
\hline Age $\geq 75$ years & 15 & 21.7 \\
\hline Diabetes mellitus & 69 & 100.0 \\
\hline Ischaemic stroke & 5 & 7.2 \\
\hline Vascular disease & 23 & 33.3 \\
\hline Age 65-74 years & 43 & 62.3 \\
\hline Female sex & & \\
\hline Bleeding risk factors (HAS-BLED) & 5 & 7.2 \\
\hline Hypertension (SBP >160 mmHg) & 12 & 17.4 \\
\hline Altered kidney function & 0 & 0.0 \\
\hline Hepatic function impairment & 69 & 100.0 \\
\hline Stroke & 0 & 0.0 \\
\hline Bleeding & 0 & 0.0 \\
\hline Labile INRs & 36 & 52.2 \\
\hline Age>65 years & 19 & 27.5 \\
\hline Antiplatelet therapy & 25 & 36.2 \\
\hline Alcohol & & \\
\hline
\end{tabular}

Table 3: Distribution of $\mathrm{CHA}_{2} \mathrm{DS}_{2}-\mathrm{Vasc}$ and HAS-BLED scores risk factors in study patients (LVEF: left ventricular ejection fraction; SBP: systolic blood pressure; INR: International Normalized Ratio).

\begin{tabular}{|l|c|c|}
\hline Treatment & Number & Percentage (\%) \\
\hline Anticoagulants & 55 & 79,7 \\
\hline LMWH alone & 19 & 27,5 \\
\hline LMWH VKA & 36 & 52,0 \\
\hline None & 14 & 20,3 \\
\hline Antiplatelet therapy & 65 & 94,2 \\
\hline Alone & 14 & 20,3 \\
\hline With VKA & 35 & 50,7 \\
\hline With LMWH & 16 & 23,2 \\
\hline None & 4 & 5,8 \\
\hline Antiarrhythmic drugs & 5 & 7,3 \\
\hline Digoxin & 14 & 20,3 \\
\hline Amiodarone & 19 & 27,5 \\
\hline B-blockers & & \\
\hline Other drugs & 55 & 79,7 \\
\hline ACE/ARBs & 51 & 74,0 \\
\hline Statins & 55 & 79,7 \\
\hline Early rehabilitation & 5 & \\
\hline
\end{tabular}

Table 4: Distribution of study treatment in 69 patients during hospitalization period (LMWH: low molecular weight heparin (enoxaparin), VKA: vitamin $\mathrm{K}$ antagonist; ACE: angiotensin-converting enzyme inhibitors; ARBs: angiotensin receptor blockers).

\begin{tabular}{|c|c|c|c|c|c|c|}
\hline \multirow{2}{*}{\multicolumn{2}{|c|}{ Factor }} & \multirow{3}{*}{$\begin{array}{l}\text { Death } \\
n / N \\
9 / 56 \\
\end{array}$} & \multicolumn{2}{|c|}{ Univariate analysis } & \multicolumn{2}{|c|}{ Multivariate analysis* } \\
\hline & & & \begin{tabular}{|l}
$\mathrm{RR}(\mathrm{Cl}$ \\
$95 \%)$
\end{tabular} & $p$ & OR (Cl 95\%) & $\mathrm{p}$ \\
\hline \multirow[b]{2}{*}{ Age (years) } & $<75$ & & 1.00 & & 1.00 & \\
\hline & $\geq 75$ & $6 / 13$ & $\begin{array}{l}2.87(1.24- \\
6.64)\end{array}$ & 0.018 & $\begin{array}{l}4.06(0.83- \\
19.68)\end{array}$ & 0.082 \\
\hline \multirow{2}{*}{$\begin{array}{l}\text { Congestive heart } \\
\text { failure }\end{array}$} & Non & $10 / 60$ & 1.00 & & 1.00 & \\
\hline & Oui & $5 / 9$ & \begin{tabular}{|l|}
$3.33(1.48-$ \\
$7.52)$
\end{tabular} & 0.019 & $\begin{array}{l}6.32(1.04- \\
38.37)\end{array}$ & 0.045 \\
\hline \multirow{2}{*}{$\begin{array}{l}\text { Haemorrhagic } \\
\text { transformation }\end{array}$} & Non & $11 / 63$ & 1.00 & & 1.00 & \\
\hline & Oui & $4 / 6$ & \begin{tabular}{|l}
$3.82(1.75-$ \\
$8.33)$
\end{tabular} & 0.018 & $\begin{array}{l}3.77(0.39- \\
36.53)\end{array}$ & 0.252 \\
\hline \multirow[b]{2}{*}{ Infarct size $(\mathrm{cm})$} & $<3$ & $6 / 51$ & 1.00 & & 1.00 & \\
\hline & $\geq 3$ & $9 / 18$ & $\begin{array}{l}4.25(1.76- \\
10.27)\end{array}$ & $<0.001$ & $\begin{array}{l}4.40(1.01- \\
19.26)\end{array}$ & 0.049 \\
\hline
\end{tabular}

Table 5: Factors associated with death on univariate and multivariate analysis in the 69 study patients during hospitalization period (RR: Risk ratio; OR: Odds Ratio; Cl 95\%: confident Interval at $95 \%$ of association measure; *Adjustment for variables listed on the table).

\begin{tabular}{|c|c|c|}
\hline & Number (n) & Percentage (\%) \\
\hline \multicolumn{3}{|l|}{ Complications } \\
\hline Haemorrhagic transformation & 6 & 8.7 \\
\hline Stroke recurrence & 2 & 2.9 \\
\hline Seizures & 6 & 8.7 \\
\hline Mesenteric infarction & 1 & 1.5 \\
\hline Venous thromboembolic disease & 1 & 1.5 \\
\hline Pressure ulcers & 1 & 1.5 \\
\hline \multicolumn{3}{|l|}{ Causes of death } \\
\hline Congestive heart failure & 4 & - \\
\hline Cerebral herniation & 3 & - \\
\hline Haemorrhagic transformation & 2 & - \\
\hline Stroke recurrence & 2 & - \\
\hline Sepsis & 3 & - \\
\hline Mesenteric infarction & 1 & - \\
\hline
\end{tabular}

Table 6: Complications occurred during hospitalization period and immediate causes of death in all 69 patients with atrial fibrillation.

\section{Discussion}

The retrospective pattern of the study and lack of ambulatory follow up data may have underestimated the assessment of some parameters. Nevertheless current results gave an overview of the problem in our setting. All study patients did not benefit from large-artery atherosclerosis research based on the fact that it was a retrospective study and we just reported data of those who underwent this Doppler ultrasonography. Moreover Doppler ultrasonography was not performed in patients with an obvious cardiac cause of ischaemic stroke and/or in those who could not afford such exam (knowing Burkina Faso belongs to low income countries with no share care system). Arterial angiography was not available at that time.

NVAF, the most common source of cardioembolic stroke was observed in $43.5 \%$ of all cardiac causes of cerebral embolism in our study. Damorou et al. [13] in Togo and Paciaroni et al. [14] in Italia have reported lower rates in patients presenting their first episode of ischaemic stroke with respectively $19.8 \%$ and $20.3 \%$ of the cases. Conversely, Yip et al. [15] at Taiwan observed $69 \%$ of AF in a subgroup of cardioembolic stroke. Discrepancies in rates may be explained by patients' selection criteria and quality of AF screening methods used after stroke onset. A possible underuse of VKA for primary prevention of thromboembolism in AF may have played a role in low income regions such as Burkina Faso. 
Citation: Mandi DG, Samadoulougou AK, Yameogo RA, Millogo GRC, Naibe DT, et al. (2015) Non Valvular Atrial Fibrillation Related Ischaemic Stroke at the Teaching Hospital of Yalgado Ouédraogo, Burkina Faso. J Vasc Med Surg 3: 171. doi:10.4172/2329-6925.1000171

Page 4 of 5

NVAF is frequently associated with other cardiac sources of stroke which were similarly found in Kim et al. series [16] and ours with respectively $65.2 \%$ and $68 \%$ of the cases.

In a Japanese study [17] including 234 patients suffering from NVAF related stroke, AF was classified as paroxystic and permanent in respectively $42.3 \%$ and $57.7 \%$ of the cases. Our data have supported results from Marini et al. [18] study in Italia with a persistent to permanent $\mathrm{AF}$ rate being above $80 \%$. These marked differences in types of AF between studies are probably related to weight carried by 24 -hours Holter ECG in detecting paroxystic AF after ischaemic stroke onset. Regardless of the type of AF (paroxystic or permanent), the annual risk of cerebral embolism in the absence antithrombotic treatment is identical and assessed to range from 3 to $5 \%$ but widely depends on CHA2DS2-VASc score [6]. The mean CHA2DS2-VASc score in our study was 4.72 and all patients had a score $\geq 2$ indicating a very high risk of embolism and a need of antithrombotic treatment except contraindications. Moreover, bleeding risk was low to intermediate (HAS-BLED score: 1-2) in 60.9\% of our study patients suggesting safer initiation of anticoagulation therapy. This bleeding risk was high (HASBLED score $\geq 3$ ) in $39.1 \%$ of patients indicating cautious introduction of anticoagulation therapy with a close follow-up [19]. Secondary prevention of cerebral embolism in NVAF is widely addressed in series worldwide. Accordingly, it is recommended to quickly start treatment with heparinoïds in patients at very high risk of thromboembolism after an individual assessment of risk/benefit ratios [14,20,21]. For long term secondary prevention of ischaemic stroke in AF, VKA remain the gold standard treatment in reducing the risk of recurrence by 70 $\%$ [22]. In a survey of practice patterns of anticoagulation therapy in acute ischaemic stroke in Korea among physicians, the most common method of immediate treatment initiation was heparin followed by warfarin $(68 \%)$ and then warfarin alone or warfarin with aspirin in the absence of large-sized infarct and haemorrhagic transformation [23]. In the PREFER in AF study, the rate of oral anticoagulation use in 2012 was $>80 \%$ in Europe including patients at high risk of bleeding since publication of 2010 ESC Guidelines on atrial fibrillation [24]. Only $52 \%$ of our study patients benefit from VKA treatment. This relatively low rate of VKA use in our setting is partly due to physician's worry about bleeding risk and also geographic and financial constraints on accessing frequent International Normalized Ratio (INR) follow-up. However, new oral anticoagulants a great progress in therapeutics could be an alternative to VKA in a near future and modify our practice [3], due to their simpler way of use and comparative reduction of major bleeding risk $[25,26]$.

Early haemorrhagic transformation risk in AF related stroke accounts for $2.7 \%$ at one week [3]. Our results supported data from a prospective multicentric study of 1125 patients nevertheless suffering from ischaemic stroke of all origin with a rate of $8.7 \%$ and this haemorrhagic transformation is significantly associated with large-sized infarct [27]. Ischaemic stroke recurrence in AF is assessed to be $2.5 \%$ and $5 \%$ at one week and one month respectively $[2,3]$. We reported recurrence rate of $2.9 \%$ at two weeks period.

Atrial fibrillation related ischaemic stroke is classically severe with high mortality rate during the acute phase in comparison to other sources of cerebral embolism. We found in hospital rate of death $(21.7 \%)$ that supported data from literature $[2,13,28]$. Mortality was predicted by large sized cerebral infarct and congestive heart failure $(\mathrm{p}<0.05)$. Death in cardioembolic stroke is mainly due to neurological complications and cardiac comorbidities [2].

\section{Conclusion}

NVAF related stroke is associated with higher mortality during hospitalization and subject to early recurrence. A better use of international guidelines on primary and secondary prevention of cerebral embolism in AF may contribute to reduce the burden of the problem. Introduction of INR self-measurement equipment in remote areas or new oral anticoagulants could be an alternative way of treatment follow-up in rural and semi-urban areas with poorly equipped hospitals.

\section{Author's Contribution}

All authors did fully participate in the study. Paper writing process was a team work.

\section{Acknowledgment}

We are grateful to Professor Jean Kaboré and team for the close collaboration in managing patients between cardiologists and neurologists. Thank you for giving us permission to collect data at neurology department.

\section{References}

1. Mukherjee D, Patil CG (2011) Epidemiology and the global burden of stroke. World Neurosurg 76: 85-90.

2. Arboix A, Alió J (2010) Cardioembolic stroke: clinical features, specific cardiac disorders and prognosis. Curr Cardiol Rev 6: 150-161.

3. Muresan IP, Alamowitch S (2011) Prévention secondaire des infarctus cérébraux liés à l'arythmie complète par fibrillation auriculaire : quel(s) traitement(s) et dans quel(s) délai(s)? Prat Neurol - FMC 2: 6-20.

4. Lloyd-Jones D, Adams R, Carnethon M, Simone G D, Ferguson T B, et al (2009) Heart disease and stroke statistics--2009 update: a report from the American Heart Association Statistics Committee and Stroke Statistics Subcommittee. Circulation 119: 21-181.

5. Lloyd-Jones DM, Wang TJ, Leip EP, Larson M G, Levy D, et al. (2004 Lifetime risk for development of atrial fibrillation: the Framingham Heart Study. Circulation 110: 1042-1046.

6. Davy J-M, Roubille F, Tri Cung T (2010) La fibrillation atriale en 2010 : un poids croissant sur la morbidité et la mortalité cardiovasculaires. Ann Cardio Angéiologie 59: 4-13.

7. Donnan GA, Fisher M, Macleod M, Davis SM (2008) Stroke. Lancet 371: 1612 1623.

8. De los Ríos la Rosa F, Broderick JP (2013) Toward a modern delivery of stroke care in emerging economies. J Stroke Cerebrovasc Dis Off J Natl Stroke Assoc 22: $1-3$.

9. Adams HP Jr, Bendixen BH, Kappelle LJ, Biller J, Love BB, et al. (1993) Classification of subtype of acute ischemic stroke. Definitions for use in a multicenter clinical trial. TOAST. Trial of Org 10172 in Acute Stroke Treatment. Stroke J Cereb Circ 24: 35-41.

10. Lip GYH, Nieuwlaat R, Pisters R, Lane DA, Crijns H J G M (2010) Refining clinical risk stratification for predicting stroke and thromboembolism in atrial fibrillation using a novel risk factor-based approach: the euro heart survey on atrial fibrillation. Chest 137: 263-272.

11. Pisters R, Lane DA, Nieuwlaat R, Cees B de Vos, Harry JGM Crijns, et al. (2010) A novel user-friendly score (HAS-BLED) to assess 1-year risk of major bleeding in patients with atrial fibrillation: the Euro Heart Survey. Chest 138: 1093-1100.

12. Mancia G, Fagard R, Narkiewicz K, Redon J, Zanchetti A, et al. (2013) 2013 $\mathrm{ESH} / \mathrm{ESC}$ Guidelines for the management of arterial hypertension. Eur Heart J 34: 2159-2219.

13. Damorou F, Togbossi E, Pessinaba S (2008) Accidents vasculaires cérébraux (AVC) et affections cardio-vasculaires emboligènes. Mali Méd 23: 31-33.

14. Paciaroni M, Agnelli G, Micheli S, Caso V (2007) Efficacy and safety of anticoagulant treatment in acute cardioembolic stroke: a meta-analysis of randomized controlled trials. Stroke J Cereb Circ 38: 423-430. 
Citation: Mandi DG, Samadoulougou AK, Yameogo RA, Millogo GRC, Naibe DT, et al. (2015) Non Valvular Atrial Fibrillation Related Ischaemic Stroke at the Teaching Hospital of Yalgado Ouédraogo, Burkina Faso. J Vasc Med Surg 3: 171. doi:10.4172/2329-6925.1000171

15. Yip PK, Jeng JS, Lee TK (1997) Subtypes of ischemic stroke. A hospital-based stroke registry in Taiwan (SCAN-IV). Stroke J Cereb Circ 28: 2507-2512.

16. Kim YD, Park B, Cha MJ (2010) Stroke severity in concomitant cardiac sources of embolism in patients with atrial fibrillation. J Neurol Sci 298: 23-27.

17. Deguchi I, Ogawa H, Ohe $Y$ (2013) Rate of antithrombotic drug use and clinical outcomes according to CHADS2 scores in patients with an initial cardioembolic stroke who had nonvalvular atrial fibrillation. J Stroke Cerebrovasc Dis Off J Natl Stroke Assoc 22: 846-850.

18. Marini C, De Santis F, Sacco S (2005) Contribution of atrial fibrillation to incidence and outcome of ischemic stroke: results from a population-based study. Stroke J Cereb Circ 36: 1115-1119.

19. Camm AJ, Kirchhof P, Lip GYH (2010) Guidelines for the management of atrial fibrillation: the Task Force for the Management of Atrial Fibrillation of the European Society of Cardiology (ESC). Eur Heart J 31: 2369-2429.

20. European Stroke Organisation (ESO) Executive Committee, ESO Writing Committee (2008) Guidelines for management of ischaemic stroke and transient ischaemic attack 2008. Cerebrovasc Dis Basel Switz 25: 457-507.

21. Singer DE, Albers GW, Dalen JE (2008) Antithrombotic therapy in atrial fibrillation: American College of Chest Physicians Evidence-Based Clinical Practice Guidelines (8th Edition). Chest 133: 546-592.

22. Saxena R, Koudstaal PJ (2004) Anticoagulants for preventing stroke in patients with nonrheumatic atrial fibrillation and a history of stroke or transient ischaemic attack. Cochrane Database Syst Rev CD000185.
23. Lee JH, Park KY, Heo JH, Kwon SU (2011) Immediate Anticoagulation for Acute Cardioembolic Stroke is Still Popular in Selective Cases in Korea. Korean J Stroke 13: 120

24. Kirchhof P, Ammentorp B, Darius H, Caterina RD, Heuzey JL, et al. (2013) Management of atrial fibrillation in seven European countries after the publication of the 2010 ESC Guidelines on atrial fibrillation: primary results of the PREvention oF thromboemolic events--European Registry in Atrial Fibrillation (PREFER in AF). Europace 16: 6-14.

25. Bruins Slot K, Berge E (2013) Factor Xa inhibitors versus vitamin K antagonists for preventing cerebral or systemic embolism in patients with atrial fibrillation. Cochrane Database Syst Rev 8: CD008980.

26. Sardar P, Chatterjee S, Wu WC, Lichstein E, Ghosh J, et al. (2013) New oral anticoagulants are not superior to warfarin in secondary prevention of stroke or transient ischemic attacks, but lower the risk of intracranial bleeding: insights from a meta-analysis and indirect treatment comparisons. PloS One 8: 77694.

27. Paciaroni M, Agnelli G, Corea F (2008) Early hemorrhagic transformation of brain infarction: rate, predictive factors, and influence on clinical outcome: results of a prospective multicenter study. Stroke J Cereb Circ 39: 2249-2256.

28. Arboix A, García-Eroles L, Massons JB, et al. (2000) Atrial fibrillation and stroke clinical presentation of cardioembolic versus atherothrombotic infarction. Int $\mathrm{J}$ Cardiol 73: 33-42. 